\title{
A CASE STUDY ON PERFORMANCE OF RESHAPING BERM BREAKWATERS: ORDU GIRESUN INTERNATIONAL AIRPORT, TURKEY
}

\author{
Gulizar Ozyurt Tarakcioglu, Middle East Technical University, gulizar@metu.edu.tr \\ Cuneyt Baykal, Middle East Technical University, cbaykal@metu.edu.tr \\ Semih Bezazoglu, Middle East Technical University, semihbezazoglu@hotmail.com \\ Dogukan Atak, Middle East Technical University, dogukanatak@gmail.com \\ Aysen Ergin, Middle East Technical University, ergin@metu.edu.tr \\ Isikhan Guler, Middle East Technical University, isikhan@metu.edu.tr
}

\section{INTRODUCTION}

In this study, the stability and serviceability (wave overtopping) of hardly-reshaping berm breakwater of Ordu-Giresun International Airport and four alternative cross-sections of fully- and partly-reshaping berm breakwaters are assessed by physical model experiments. Ordu-Giresun International Airport is a public airport constructed on an approximately $1.77 \mathrm{~km}$ square reclaimed land at the eastern Black Sea coast of Turkey. The reclaimed land area is protected with a 7345 $\mathrm{m}$ long hardly reshaping rubble mound berm breakwater at a depth of $11 \mathrm{~m}$ (MSL). The design high water level (HWL) corresponding to $100-y r$ return period is calculated as $+1.12 \mathrm{~m}$. The bottom slope from deep water up to 20 $m$ water depth is around 1:50 and becomes steeper (1:20) towards the shore. The design wave characteristics at the toe of the structure (100-yr return period) is determined as $\mathrm{H}_{\mathrm{s}}=6.68 \mathrm{~m}, \mathrm{~T}_{\mathrm{m}}=10.80 \mathrm{sec}$.

\section{EXPERIMENTS}

The physical model experiments are conducted in the wave flume of Middle East Technical University (METU), Department of Civil Engineering, Coastal and Ocean Engineering Laboratory. The model length scale is determined as $\lambda_{L}=1: 32.8625$ applying Froude similarity. The cross sections (Figure 1) were subject to wave trains of 1000 irregular waves (100-yr return period and HWL). Wave trains of 10000 waves were also used to observe cumulative damage development under the same design wave conditions.

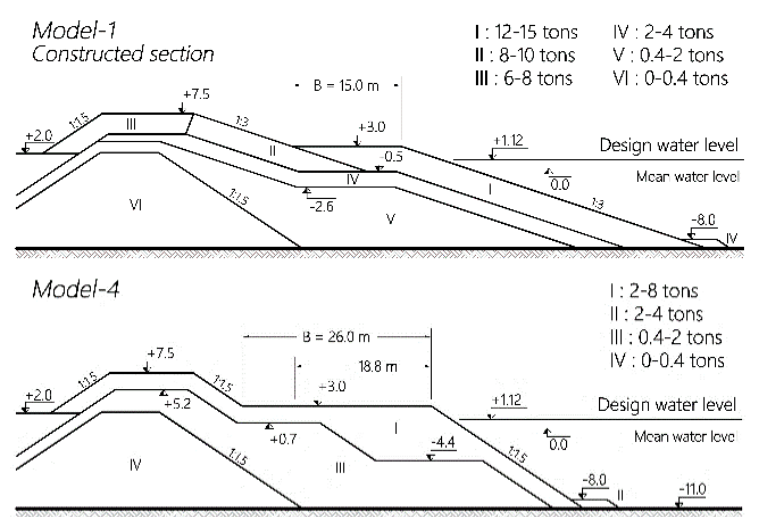

Figure 1 - Examples of test cross sections (original sectionModel 1 and fully reshaping section - Model 4)

Model 1 is the constructed hardly shaping berm breakwater, which has a very large base and 12-15 $t$ of armour stones. Model 2 is designed to have minimum berm width with armour stones of 2-4 t. Model 3 again has $2-4 \mathrm{t}$ of armour stone but a larger berm $(26 \mathrm{~m})$. Models 4 and 5 have the same berm width as Model 3 however
Model 4 is a fully reshaping section with $2-8 \mathrm{t}$ of armour whereas Model 5 is partly reshaping with $6-10$ t of armour stones, Mean overtopping discharges (measured at every 500 waves), and cross-section profile measurements (using laser meter before and after each test and video footage) are used to assess the stability and serviceability of the alternative design sections compared to the original section.

\section{CONCLUSIONS}

The stability of the alternately designed sections are evaluated based on their recessions and damage parameters observed in the experiments. Except Model 2 which failed, all the alternative sections experienced damage within the limits given in van der Meer and Sigurdarson (2016). The recessions in the experiments are slightly less than the computed recessions by Lykke Andersen et al.'s (2014) formulation but stays within 90\% confidence limits of the computed values. This discrepancy could be related to i) the quite long berm width to minimize the wave overtopping and ii) gentler front slopes (1:1.5) below the berms than the slopes (1:1.25) used in Lykke Andersen's experiments (2006). It is seen that recessions obtained from video footage do not change significantly after 7000-8000 waves for Models 3, 4 and 5 suggesting that the profiles had reached to equilibrium.

The measured overtopping discharges are less than the computed values with an order of magnitude of 10 on average using either Sigurdarson and van der Meer (2012) or Lykke Andersen (2006) formulas, except for the Model 2. This discrepancy is probably related to the increased flow resistance due to long berm widths of Model 3-5 or the overall section length of the Model 1 with its much gentler front slope of 1:3. Also, the overtopping discharge rates are observed to fluctuate slightly before 7000 waves in the 10000 wave long sets which could suggest that the reshaping process until the equilibrium could affect the serviceability of these structures.

\section{REFERENCES}

Andersen, Moghim, Burcharth, (2014) Revised recession of reshaping berm breakwaters. Proc. 34rd Int. Conf. on Coastal Eng. ASCE, Seoul, Korea.

Sigurdarson, Van der Meer. (2012). Wave overtopping at berm breakwaters in line with EurOtop, Proc. 33th Conf. Coastal Eng., ASCE.

Van der Meer, Sigurdarson (2016) Design and Construction of Berm Breakwaters. World Scientific. 